\title{
The Impact of the Covid-19 Pandemic on Boursa Kuwait Return Volatility
}

\author{
Mesfer Mahdi Al Mesfer Al Ajmi \\ Department of Banking and Insurance, College of Business Studies, PAAET, Kuwait \\ *Correspondence: Mesfer Mahdi Al Mesfer Al Ajmi, Tel: 00965-67057726; Email: mesfer.almesfer@yahoo.com
}

\begin{abstract}
The main objective of this research is to detect the impact of COVID-19 on return volatility of Boursa Kuwait main indexes using EGARCH and TGARCH models on the daily data from the All Share, Premier and Main indexes. The mean return during COVID-19 from February 24 to August 31, 2020, for the three indexes was negative with a high volatility value in the standard deviation compared to a positive return and low standard deviation for the period January 2, 2019, to February 23, 2020. Both periods' returns for the market indexes exhibited negative skewness, large kurtosis values and abnormal distributions. There were significant EGARCH negative values during the COVID-19 period in the All Share and Premier indexes indicating leverage effects. The Main index reflected positive significant values due to the positive effects of government procedures that were implemented to counter the pandemic. The TGARCH model indicated significant negative values for the All Share and Main indexes during COVID-19 with decreased volatility when positive news on COVID-19 was announced. Using the threshold generalized autoregressive conditional heteroscedasticity (TGARCH) the Premier index value is positive and signific ant indicating an asymmetric effect showing that volatility increased when negative news on COVID-19 was broadcast. This is an important inference for market participants and policy makers particularly when there is a difference in the magnitude of an asymmetry.
\end{abstract}

KEYWORDS: COVID-19, Boursa Kuwait, Asymmetric Effects, Volatility Modelling

\begin{tabular}{|c|c|}
\hline \multicolumn{2}{|l|}{ ARTICLE INFORMATION } \\
\hline \multirow{3}{*}{$\begin{array}{l}\text { Author(s): Mesfer Mahdi Al Mesfer Al Ajn } \\
\text { Received: } 24 \text { Nov, 2021; Accepted: } 13 \text { Dec, 2021; } \\
\text { e-ISSN: 2347-4696; } \\
\text { Paper Id: BMN-IJBMR-2021-78; } \\
\text { Citation: doi.org/10.37391/IJBMR.090411 } \\
\text { Webpage-link: }\end{array}$} & \\
\hline & Crossef member \\
\hline & $\begin{array}{l}\text { CROSSREFOORG } \\
\text { THECTTATOONUNKNG BACKBONE }\end{array}$ \\
\hline
\end{tabular}

\section{INTRODUCTION}

\subsection{COVID-19 overview}

There is a huge economic impact of COVID-19 on the world economy compared to the famous pandemic of the $21 \mathrm{st}$ century in 2002, severe acute respiratory syndrome (SARS), and other diseases. This pandemic started when the Chinese City of Wuhan witnessed the outbreak of COVID-19 during December 2019 followed by reports of global increases in confirmed cases in different countries. The World Health Organization (WHO) first issued an alert about COVID-19 on January 30, 2020. When the disease became known as a highly contagious disease in the world, with high numbers of infected cases, the World Health Organization (WHO) announced on March 11, 2020, that COVID-19 was a pandemic disease that had emerged as a worldwide crisis.

The outbreak led to lockdowns and travel restrictions, employees could not go to work, movement of goods and services were curtailed, many economic activities were shut down, and other measures were taken that resulted in negative consequences on the world at both the economic and state levels. COVID-19 impacted some industries more than others and domestic demand was affected in most countries (Goodell, 2020). Additionally, the performance of stock markets during the year 2020 declined as reflected by the values of stock markets indexes. The fundamental values of companies listed on international stock markets had not changed, but their values were reduced by the impact of a big crises, similar to this pandemic (Hoshi \& Kashyap, 2004) which makes analyzing the stock markets difficult. Table 1 presents the performance of a number of international stock market indexes during the pandemic which shows that the value of the Dow Jones Industrial Average index of the New York Stock Exchange had declined by $23.2 \%$ the Dax index of the Frankfurt Stock Exchange declined by $33.05 \%$, and the FTSE index of the London Stock Exchange declined by $30.48 \%$. Additionally, the All Share Price index of Boursa Kuwait decreased during the COVID-19 period with a drop of almost $29 \%$.

Table 1. International Stock Market Index Values

\begin{tabular}{lcrr}
\hline Index Name & Country & $\begin{array}{r}\text { December } \\
2019\end{array}$ & March 2020 \\
\hline Dow Jones & USA & 28538.44 & 21917.16 \\
Dax Index & Germany & 13337.11 & 8928.95 \\
FTSE 100 & UK & 7466.90 & 5190.78 \\
Index & & 7235.00 & 5134.79 \\
All Share & Kuwait & & \\
Index & & & \\
\hline
\end{tabular}

In Kuwait the first cases of COVID-19 were reported on February 24, 2020, after passengers arrived at Kuwait Airport from neighboring countries, infected with COVID-19. The outbreak of COVID-19 caused health officials in Kuwait to impose procedures on social distancing, implement a full lockdown and then a partial lockdown to control the spread of this disease similar to many other governments. On August 30, 
the partial lockdown was lifted. During December 2020 a scheme for vaccinating everyone in Kuwait against COVID-19 was started which had a positive effect on the recovery of the economy and related activities.

\subsection{Kuwait stock exchange}

Stock trading has undergone several stages culminating in the establishment of the Kuwait Stock Exchange in 1983 as a modern stock exchange. It was privatized in 2016 and its name was changed to Boursa Kuwait. The main indexes of Boursa Kuwait are the All Share Market, Premier and Main indexes. The All Share index includes all the shares listed on Boursa Kuwait. The Main Market index includes all the companies listed on the Main Market which are not entitled to be listed on the Premier market. Member companies entitled to be listed on the primary market is regarded as the best companies in Boursa Kuwait due to the high requirements imposed by Boursa Kuwait such as having yearly market capitalizations of at least 78 million KD, being in operation for at least 7 years, and having to comply annually with tough requirements including Boursa liquidity requirements. Companies which are members of the primary market are included on the Primary index and some of them are included on the Main Market index. The member companies in the Main Market are included in the Main Market index and the All Share indexes.

By the end of 2019, 175 companies traded on Boursa Kuwait with a combined market capitalization of 35798 million KD. By the end of 2020, 171 companies traded on Boursa Kuwait with a combined market capitalization of 32320 million KD. Further statistics can be seen on Table 2. Currently Boursa Kuwait has 13 different sectors.

Table 2. Boursa Kuwait Summary Statistics

\begin{tabular}{|c|c|c|c|}
\hline & 2019 & 2020 & $\begin{array}{l}\% \\
\text { Change }\end{array}$ \\
\hline All Share Index & 6282 & 5546 & $-11.7 \%$ \\
\hline Number of Trading days & 250 & 242 & $-3.2 \%$ \\
\hline Number of Trades & $\begin{array}{r}1545 \\
128\end{array}$ & $\begin{array}{r}2318 \\
050\end{array}$ & $50.2 \%$ \\
\hline $\begin{array}{l}\text { Volume of Traded Shares } \\
\text { (Million) }\end{array}$ & 39047 & 52095 & $33.4 \%$ \\
\hline $\begin{array}{l}\text { Value of Traded Shares } \\
\text { (Million) }\end{array}$ & 7938 & 10752 & $35.4 \%$ \\
\hline $\begin{array}{l}\text { Average Daily Traded Value } \\
\text { (KD Million) }\end{array}$ & 31.8 & 44.8 & $39.4 \%$ \\
\hline $\begin{array}{l}\text { Market capitalization (KD } \\
\text { Million) }\end{array}$ & 35798 & 32320 & $-10 \%$ \\
\hline Number of Listed Companies & 175 & 171 & $-2.3 \%$ \\
\hline
\end{tabular}

Source: Boursa Kuwait Annual Report 2020

\subsection{Measuring volatility}

Studying the volatility of the stock market is important to investors who need a measurable tool for the variation in prices and associated risks. Black and Scholes (1975) indicated that a negative shock on a conditional variance is called a leverage effect because it increased volatility compared to positive shocks. The degree by which a trading price fluctuates over time is viewed as volatility and when these volatility values are low, they indicate that stock values do not change short term (Glosten, Jagannathan, \& Runkle, 1993). Various studies used generalized autoregressive conditional heteroskedasticity (GARCH) models to test volatility in developed and emerging stock market main indexes. They have been used to a lesser extent to measure the volatility of stock markets sectors. Al Mesfer Al Ajmi (2021) is this far the only study to investigate the volatility of stock market sectors using GARCH models on the daily data from Boursa Kuwait for 2012 to 2018.

Empirical studies on the impact of COVID-19 on developed and emerging stock markets are limited. However, more studies are being conducted, which created an incentive to research and understand this impact on Boursa Kuwait Main Market indexes. The methodology used is the EGARCH and TGARCH models, which to the best of my knowledge the only study is using this methodology for the COVID-19 period. Therefore, this study fills a gap in the literature.

\subsection{GARCH Models in the literature}

Volatility refers to the fluctuations of stock index prices over a period of time and several scholars have investigated modelling stock market volatility (conditional variances) to determine accurate estimations. Their findings are important to analysts, investors and policy makers. A review of the progress in applying GARCH models, as volatility models, is presented with selected studies that applied the GARCH models during COVID-19.

Engle (1982) pioneered the work by developing an autoregressive conditional heteroscedasticity (ARCH) model. Bollerslev (1986) built on Engle's model and developed the GARCH model. These two models are regarded as the standard models for assessing symmetric volatility of stock market returns by accounting for time series heteroscedasticity in treating the variances as non-stationary. However, the limitation of these two models is not being able to assess the leverage and asymmetric effects in a time series.

To overcome this limitation, Nelson (1991) introduced the exponential GARCH (EGARCH) model to measure the leverage effect on stock market returns. Two further models were developed to identify the relationship between asymmetric volatility and returns, namely the GJR-GARCH model proposed by Glosten et al. (1993) and the Threshold ARCH (TGARCH) model proposed independently by Zakoian (1994). The TGARCH model is able to investigate the effects of positive and negative shocks on return volatility and is comparable to the GJR-GARCH model. To deal with the asymmetric effects on volatility, the Power GARCH (PGARCH) was proposed by Ding et al. (1993) and the 
quadratic GARCH model was introduced by Sentana (1995) and other researchers continued on this topic.

\subsection{Using GARCH to measure volatility in the literature}

The accuracy of GARCH model results led to this model becoming the customary method for modelling volatility in financial time-series data (Brooks \& Rew, 2002). Poon and Granger (2003), in their in-depth review of different methodologies, reviewed 93 forecasting volatility studies and emphasized the importance and usefulness of $\mathrm{ARCH}$ and GARCH time-series models in predicting volatility.

Studies on the GARCH volatility models were tested on developed and emerging markets before the COVID-19 pandemic. These studies include the Australian market by Nicholls and Tonuri (1995), the US market by Bekaert and WU (2000), the UK market by McMillan and Speight (2003), the Japanese market by Choo, Lee and Ung (2011), the Nigerian market by Ogege (2016), the Indian, Chinese, Indonesian, Sri Lankan, Pakistani, Russian, Brazilian, South Korean, Mexican, and Hong Kong Markets by Sanyal and Gahan (2016), the UK, French and German markets by Olbrys and Majewska (2017) and the Kuwaiti market by Al Mesfer Al Ajmi (2021).

\subsection{Measuring volatility during COVID-19 in the literature}

There are studies on testing volatility in times of crises but this review focuses on volatility during COVID-19 where there are a limited, but growing, number of studies on the impact of COVID-19 that use the volatility GARCH models. Yousef and Shehadeh (2020) analyzed the effect of COVID-19 on the volatility of gold returns, using daily spot prices collected from Thomson Reuters for the period 2012 to 2020. They found that the ARCH and GJR-GARCH models showed a significant positive impact of COVID-19 on the volatility of gold returns. The uncertainty about the future, as COVID-19 spread, caused an increase in the demand for gold which resulted in an increase in gold prices.

The GARCH, EGARCH and TGARCH models were used by Ganguly (2020) to test the volatility and leverage effects during the COVID-19 outbreak on the international stock markets of France, Germany, India, Italy, Russia, Spain, UK, and the USA. The study results, using the GARCH model on the daily index prices of these markets from January 1 to June 26, 2020, showed a volatility in all of the markets except the Russian market. The EGARCH and TGARCH model results did not show a leverage effect in these markets.

Czech, Wielechowski, Kotyza, Benešová, and Laputková (2020) used the daily returns from January 1, 2014 to May 7, 2020 of the blue-chip stock market indices to assess the impact of coronavirus on the financial markets of the Visegrád group countries: the Czech Republic, Hungary, Poland, and Slovakia. When applying the TGARCH model, they found that an increase in COVID-19 cases resulted in a decline in the main stock markets indexes.

Chaudhary, Bakhshi, and Gupta (2020) studied the effect of
COVID-19 on the stock market indexes of the ten countries with the largest GDPs: US, China, Japan, Germany, India, UK, France, Italy, Brazil, and Canada. A negative mean was reported with a higher standard deviation. Using the GARCH model on the returns from the daily data for January 2019 to June 2020, the values were positive and significant indicating increased volatility during that period.

Yong, Ziaei, and Szulczyk (2021) used the daily data from July 1, 2019 to August 31, 2020 of the indexes of Malaysia and Singapore and their results showed positive values using EGARCH and TGARCH in the Malaysian and Singaporean indexes indicating that the negative news was more dominant during the COVID-19 period.

Bora and Basistha (2021) studied the NSE Nifty and BSE Sensex indexes in India to measure the effect of COVID-19 using the GJR GARCH model. Descriptive statistics were given for both periods before the COVID-19 period from September 3, 2019, to January 29, 2020, and during the outbreak of COVID-19 in January 30, 2020, to October 6, 2020. Before COVID-19 a positive return and a small standard deviation were noticed. A negative return and higher standard deviation were shown during COVID-19. The asymmetric significant positive values for both indexes, based on the daily data for the period January 30, 2020, to October 6, 2020, indicated that negative news about COVID-19 had a larger effect and confirmed that India' two stock markets endured volatility during the COVID-19 period.

Alzyadat, Abuhommous, and Alqaralleh (2021) used the daily closing prices of indexes in the Saudi market covering the period from September 2017 to September 2020. Their results, using several GARCH models, NGARCH, NAGARCH, APARCH, and GJR-GARCH, showed an inverted effect on the index returns before COVID-19 and strong evidence of asymmetry throughout the COVID-19 period starting from January 2, 2020, to December 17, 2020.

\subsection{The effects of good and bad news}

Onyele and Nwadike (2021) analyzed the daily returns of the S\&P Global 1200 index from September 1, 2010, to September 30, 2021, using the GARCH-M and TGARCH models. A volatility persistence was shown caused by the influence of current volatility shocks on the expected returns over a long period of time. GARCH-M results showed a tradeoff between risk and return. TGARCH model values reflected that negative news had more impact on stock return volatility than good news especially through the COVID-19 period in 2020.

Nurdany, Ibrahim, and Romadoni (2021) investigated the asymmetric effect on the Indonesia Islamic Capital market by using the daily closing prices from January 2, 2020, to July 17, 2020, of the Indonesia Sharia Stock Index (ISSI). Their GARCH $(1,1)$ showed that the present values of ISSI did not have the ability to cause a substantial effect on the future values. The results also indicated the presence of volatility in the returns of the ISSI. A positive value using TGARCH $(1,1)$ 
was reported indicating that good news had a larger effect than bad news.

Yong et. al. (2021) estimated the volatility of the markets in Singapore and Malaysia using the daily-return data from July 1, 2019, to August 31, 2020. The GARCH result for the returns in both markets showed persistent decreases during the pandemic period. The positive significant values of EGARCH models for the two markets indicated a leverage effect meaning the market returns were negatively correlated with volatility.

\section{METHOD}

\subsection{Data}

The daily-closing-prices data for market indexes of the All share, Premier and Main were obtained from the official site of Boursa Kuwait for January 2, 2019, to August 31, 2020, to compare the descriptive statistics before COVID-19 and during COVID-19 from February 24, 2020, to August 31, 2020. Selecting this period gives a good understanding of the behavior of Boursa Kuwait. The methodology used to assess the asymmetric effect of the impact of COVID-19 for the period February 24, 2020, to August 31, 2020, is the EGARCH and TGARCH models because the first cases of COVID-19 were reported by the Ministry of Kuwait Health on February 24, 2020.
The rate of return of the daily closing index prices is in Kuwaiti Dinar and calculated as the logarithm of successive price relatives to avoid non-stationarity in raw index price data. EViews software was used to obtain GARCH models results.

\subsection{Statistical Representation}

The descriptive statistics generated are the mean, standard deviation, kurtosis, skewness, and the normality statistics Jarque-Bera test to have inference about the distribution of the three indexes' returns.

Table 3 presents the statistics before COVID-19 from January 2, 2019, to February 23, 2020. The means of the three indexes are positive and the Premier index has a higher value. The standard deviation values reflect a higher value for the Premier index indicating higher volatility and a relatively higher return. The distribution of the returns is skewed to the left and the distribution of the returns are also peaked to the left. The Kurtosis values are noticeably higher. The Jarque-Bera test, with respected probabilities, indicates that the daily returns of the three indexes were not normally distributed before the COVID-19 period.

Table 3. Descriptive Statistics before COVID-19 Period from $1 / 2 / 2019$ to $2 / 23 / 2020$

\begin{tabular}{|c|c|c|c|c|c|c|}
\hline \multirow[t]{2}{*}{ Statistics } & \multicolumn{3}{|c|}{$1 / 2 / 2019$ to $2 / 23 / 2020$} & \multicolumn{3}{|c|}{$2 / 24 / 2020$ to $8 / 27 / 2020$} \\
\hline & $\begin{array}{l}\text { Main } \\
\text { Market } \\
\text { Index }\end{array}$ & $\begin{array}{l}\text { Premier } \\
\text { Market } \\
\text { Index }\end{array}$ & $\begin{array}{c}\text { All Share Market } \\
\text { Index }\end{array}$ & $\begin{array}{l}\text { Main } \\
\text { Market } \\
\text { Index }\end{array}$ & $\begin{array}{c}\text { Premier } \\
\text { Market } \\
\text { Index }\end{array}$ & All Share Market Index \\
\hline Mean & 0.000215 & 0.001052 & 0.000818 & -0.000935 & -0.000945 & -0.000944 \\
\hline Std. Dev. & 0.004533 & 0.007809 & 0.006386 & 0.009045 & 0.024860 & 0.020209 \\
\hline Skewness & -0.815806 & -0.760181 & -0.944505 & -2.015827 & -1.990711 & -2.116696 \\
\hline Kurtosis & 8.918698 & 6.800163 & 8.304234 & 10.94853 & 11.14905 & 11.58870 \\
\hline Jarque-Bera & 446.0356 & 198.2408 & 375.1553 & 400.4762 & 414.7213 & 462.2573 \\
\hline Probability & 0.000000 & 0.000000 & 0.000000 & 0.000000 & 0.000000 & 0.000000 \\
\hline Observations & 284 & 284 & 284 & 121 & 121 & 121 \\
\hline
\end{tabular}

During the COVID-19 period from February 24, 2020 to August 31, 2020 all the means presented on Table 3 are negative for the three indexes which indicate losses in the returns of these indexes. The standard deviation values showed larger increases in comparison to the period before COVID-19 indicating higher volatility. This is a similar result to the study of Ganguly (2020). The skewness values are negative and reflect increased values in comparison to the period before COVID-19 confirming that the distributions are skewed to the left. The kurtosis values are peaked (leptokurtic) with high values indicating possible losses in the returns of these indexes. The normality test values of Jarque-Bera test showed a significance at $1 \%$ level for all three indexes and this confirms that the index distributions are not normally distributed, similar to the findings of Ganguly (2020) on international stock markets.

\subsection{Methodology}

The main methodology is to use the asymmetric GARCH models of EGARCH and TGARCH to understand the volatility and the asymmetric impact during COVID-19 on Boursa Kuwait. 
The GARCH model is explained to create a link to the EGARCH and TGARCH models that are specified in this section. The GARCH model is an extension of the ARCH model (Engle 1982) which assumes that estimating changes in variances over time depend on the lagged variances of financial assets. Fluctuations in returns at time ${ }^{t}$ will lead to fluctuations in volatility in future periods. Bollerslev (1986) extended the ARCH model to the GARCH model. The $\operatorname{GARCH}(1,1)$ is written as follows:

$$
r_{\mathrm{t}}=\mu_{+} \varepsilon_{\mathrm{t}}
$$

Equation 1 is the mean equation with the return $r_{t}$, the average return is ${ }^{\mu}$ and the residual returns is $\varepsilon_{t}$.

$$
\sigma_{t}^{2}=\omega_{+} \alpha \varepsilon_{\mathrm{t}-1}^{2}+\beta{ }_{t-1}^{2}
$$

Equation 2 is the conditional variance equation $\sigma_{t}^{2}, \omega$ is the constant term, $\varepsilon_{\mathrm{t}-1}^{2}$ is the lagged square from the mean equation (ARCH term) used to assess the news on volatility from the previous period, and $\sigma_{t-1}^{2}$ is the forecasted variance of the last period (GARCH term).

The required GARCH $(1,1)$ constraints needed to have positive $^{\sigma_{t}^{2}}$ are $\omega>0, \alpha \geq 0, \beta \geq 0$. The conditional variance ARCH effect $(\alpha)$ is used to estimate the response to shock and the GARCH effect $(\beta)$ is used to measure the duration of time for the change to happen. A high value in $\alpha$ indicates heightened sensitivity to new information and high values in $\beta$ indicate that these changes will linger for a long time. High values in $\mathrm{ARCH}$ and GARCH, when added together, indicate a high persistence in the related time series.

The shortcoming in symmetric GARCH, of not being able to deal with asymmetric effects, directed Nelson (1991) to develop the exponential GARCH model (EGARCH) to determine the asymmetric effects of good and bad news on volatility. This EGARCH $(1,1)$ model is used in this study to test the asymmetric effects during the COVID-19 period and it is constructed on a logarithmic expression of the conditional variance as follows:

$\log \left(\sigma_{t}^{2}\right)=\omega+\beta\left(\sigma_{t-1}^{2}\right)+\alpha\left|\frac{\varepsilon_{t-1}}{\sigma_{t-1}}\right|-\gamma \frac{\varepsilon_{t-1}}{\sigma_{t-1}}$

The constant is $\omega, \varepsilon_{\mathrm{t}-1}$ is the prior square error term $(\mathrm{ARCH})$ and, $\sigma_{\mathrm{t}-1}$ is the prior period conditional variance $(\mathrm{GARCH})$.

In Equation 3 the $\log$ forecasted conditional variance is $\sigma_{t}^{2}$ which indicates that the leverage is exponential. A negative 1 in the EGARCH model indicates negative news which results in larger impacts on volatility than positive news while a statistically zero value in $\gamma$ indicates the effects are symmetric.

The changes in the news in terms of bad news (negative return shock) or good news (positive return shock) on volatility were measured using the TGARCH model (Zakoian, 1994) and the GJR model (Glosten et al., 1993). The TGARCH model added the asymmetric effects to the standard GARCH model where the conditional variance specification in TGARCH model $(1,1)$ is assumed as follows:

$\sigma_{\mathrm{t}}^{2}=\omega+\alpha \varepsilon_{\mathrm{t}-1}^{2}+\beta \sigma_{\mathrm{t}-1}^{2}+\gamma \varepsilon_{\mathrm{t}-1}^{2} \mathrm{~d}_{\mathrm{t}-1}$

$\sigma_{\mathrm{t}}^{2}$ is the forecasted conditional variance where $\omega$ is the constant, $\varepsilon_{\mathrm{t}-1}$ is the prior square error term $(\mathrm{ARCH})$ and, $\sigma_{\mathrm{t}-1}$ is the prior conditional variance term $(\mathrm{GARCH})$.

To distinguish between good and bad news, the dummy variable $\mathrm{d}_{\mathrm{t}}$ is used. That is $\mathrm{d}_{\mathrm{t}}=1 \varepsilon_{t-1}<0$ indicates bad news $\mathrm{d}_{\mathrm{t}}=0 \varepsilon_{t-1} \geq 0$ indicates good news and they will have differential effects on conditional variances.

The leverage parameter $\gamma$ will increase when $\gamma>0$, the sign of $\gamma$ should be positive and that indicates negative shocks (bad news) have larger effects on $\sigma_{\mathrm{t}}^{2}$, which will make the volatility measures rise in $\gamma \varepsilon_{\mathrm{t}-1}^{2}$. Good news has an impact of $\alpha$, and bad news has an impact of $\alpha+\gamma$. Therefore, the type of news affects volatility differently.

\section{RESULTS}

\subsection{Stationarity and ARCH Tests}

Before modelling the asymmetric effect (volatility) using EGARCH and TGARCH models, the data was tested for stationarity and for the required $\mathrm{ARCH}$ effects. A stationarity test is performed to check the stability of the mean, variance, and autocorrelation because data stationarity indicates that there are no changes over time. The standard Augmented Dickey-Fuller (ADF) test (Dickey \& Fuller, 1981) is used to test for the stationarity of the data.

The Lagrange Multiplier Heteroskedasticity test was applied following the model of Engle (1982) to determine whether there is autoregressive conditional heteroscedasticity (ARCH) in the residual of each one of the three indexes' returns.

Stationarity in the data and the presence of $\mathrm{ARCH}$ in the residual data are presented in Table 4 . The stationarity results for the three indexes have significant values at $1 \%, 5 \%$, and $10 \%$ levels in the ADF test. Additionally, an arch effect in the index returns can be seen from the significant values in the ARCH LM test for all three indexes. After obtaining the results on the stationarity of the data and finding evidence of an arch effect on the three indexes' returns, a test for asymmetric effects is implemented using EGARCH and TGARCH models.

Table 4. Stationarity and ARCH Tests during COVID-19 Period from $2 / 24 / 2020$ to $12 / 31 / 2020$ 
Prob.

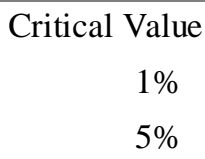

Critical Value

$1 \%$

$5 \%$

$10 \%$
ARCH-LM

(p-VALUE)

\begin{tabular}{llllrr}
\hline All Share Index & & -8.811528 & 0.0000 & -3.485586 & 14.06909 \\
& 1\% level & -3.485586 & & -2.885654 & 0.0002 \\
& 5\% level & -2.885654 & & -2.579708 & \\
& $10 \%$ level & -2.579708 & & & 14.51438 \\
\hline Premier Market Index & & -8.998978 & 0.0000 & -3.485586 & 0.0001 \\
& 1\% level & -3.485586 & & -2.885654 & \\
& 5\% level & -2.885654 & & -2.579708 & 11.13371 \\
& $10 \%$ level & -2.579708 & & & 0.0011 \\
\hline Main Market Index & & -7.878585 & 0.0000 & -3.485586 & -2.885654 \\
& 1\% level & -3.485586 & & -2.579708 &
\end{tabular}

*Under the null hypothesis of no heteroskedasticity, the Chi-square distribution is significant at 1\%, 5\%, and 10\%.

\subsection{EGARCH Model}

Tables 5 and 6 present the values of the EGARCH and TGARCH models during the COVID-19 period. These two models enable us to test whether the news and events have leverage and asymmetric effects on the market index returns by measuring the good effects (positive shocks) and bad effects (negative shocks).

The sum of the significant ARCH and GARCH values in the EGARCH model for the All Share and Premier indexes shown on Table 5 do not show a presence of ARCH and GARCH shocks on volatility. The Premier index persistence value during the COVID-19 period is the lowest indicating a decrease in memory. The EGARCH sum of the ARCH and GARCH values for the Main index, is significant and more than one shows a strong persistence shock on volatility and the volatility of the conditional variance. This is similar to the findings of Ganguly (2020), specifically on the Italian Market during COVID-19.

$\begin{array}{lll}\text { Indexes } & \text { Mean } & \text { Variance Equation } \\ & \text { Equation }\end{array}$

Index

C

The EGARCH values of $(\gamma)$ on Table 5 for the All Share and Premier indexes are significant and negative indicating leverage effects, during the pandemic, on their returns corresponding with negative news on COVID-19. The indexes were less affected by positive news. The Main Market index value has a significant positive EGARCH value which indicates that this index's return is more affected by positive news from the Kuwait Government during the pandemic. This positive Main index result is similar to the positive value in the EGARCH model used in studying the Malaysian and Singapore Markets by Yong et al. (2021). The significance of the leverage value is an important indicator for investors to alert them to negative behavior seen in the returns of the indexes during COVID-19.

Table 5. EGARCH $(1,1)$ Results during COVID-19 Period

\begin{tabular}{lrrrrrrr}
\hline All Share & 0.000955 & -11.53255 & 0.652502 & -0.343069 & -0.273212 & 0.309433 & 0.070790 \\
& 0.5634 & 0.0000 & 0.0002 & 0.0024 & $0.0653^{*}$ & $(0.7902)$ \\
\hline Premier & 0.001746 & -11.22722 & 0.465258 & -0.401827 & -0.282053 & 0.0183205 & 0.000115 \\
& 0.4401 & 0.0000 & 0.0174 & 0.0007 & $0.0950^{*}$ & $(0.9915)$ \\
\hline Main & 0.000343 & -0.957587 & 0.661871 & 0.955971 & 0.157419 & 1.617842 & 0.288400 \\
& 0.3509 & 0.0001 & 0.0000 & 0.0000 & $0.0537 *$ & $(0.5137)$ \\
\hline
\end{tabular}




\subsection{The TGARCH Model}

The GARCH values on the TGARCH model on Table 6 shows a high value for of the All Share index indicating longer periods of volatility applicable to the index. The Main index result for the TGARCH value for the stationarity condition (persistence) is more than one indicating a longer period of volatility.

The ARCH effect, as reflected in the results of the EGARCH and TGARCH models, shows higher values for the Main index indicating the $\mathrm{ARCH}$ effect from the earlier period is more likely to endure in this index than in the other two indexes.

The values of $\gamma$ for the TGARCH model during the COVID-19 period, representing the asymmetric performance, are presented on Table 6. The results show significant negative values for $\gamma$ in the All Share and Main indexes indicating positive asymmetric effects during the COVID-19 period. This is an indication that good news causes an improvement in the

Indexes Mean

Equation

\begin{tabular}{lrrrrrrr}
\hline Index & $\mathrm{C}$ & Constant & $\begin{array}{r}\text { Arch Effect } \\
-\alpha\end{array}$ & $\begin{array}{r}\text { GARCH } \\
\text { Effect }-\beta\end{array}$ & Leverage $\gamma$ & Persistence & $\begin{array}{r}\text { Residual } \\
\text { Diagnostics: } \\
\text { Arch-LM } \\
\text { Value }\end{array}$ \\
\hline All Share & 0.001640 & $4.66 \mathrm{E}-06$ & -0.071271 & 1.021569 & -0.013950 & 0.950298 & 0.195402 \\
& 0.0915 & 0.0000 & 0.0000 & 0.0000 & $0.0000^{*}$ & & $(0.6585)$ \\
\hline Premier & 0.001200 & $9.30 \mathrm{E}-06$ & -0.097491 & 0.992874 & 0.049668 & 0.895383 & 0.790165 \\
& 0.3918 & 0.0000 & 0.0036 & 0.0000 & $0.0000^{*}$ & & $(0.3741)$ \\
\hline Main & 0.000413 & $1.70 \mathrm{E}-06$ & 0.581533 & 0.642165 & -0.373438 & 1.223698 & 0.288400 \\
& 0.3123 & 0.1042 & 0.0100 & 0.0000 & $0.0626^{*}$ & & $(0.5912)$
\end{tabular}

*Significant at a $10 \%$ level.

The result of the residual diagnostic is presented at the last column of Tables 5 and 6 . When there are significant values in the ARCH LM test, it confirms the hypothesis that there are no ARCH effects when using the asymmetric models of EGARCH and the TGARCH.

\section{CONCLUSIONS}

This study presents a new finding on the impact of the COVID-19 pandemic on the volatility of the stock market returns of Boursa Kuwait. The descriptive statistics analysis revealed the index returns were not normally distributed before and during the COVID-19 periods and that the three indexes were more volatile during COVID-19 as reflected by the values in the standard deviations.

Because volatility clustering is found, a GARCH effect is included in the volatility estimation during the COVID-19 period using the asymmetric EGARCH and TGARCH models to assess the effects of good and bad news on each of the three indexes: All Share, Premier and Main. The asymmetric returns of the two indexes and it is more prevalent than the impact of bad news on COVID-19. These values indicate that the leverage effect was not applicable to these two inde xes.

The Premier index value has a significantly positive value in the TGARCH model which is different from zero as can be seen on Table 6. This indicates that negative news on COVID19 has a negative effect on the conditional volatility of the index returns, more so than good news does. This is similar to the findings of Yong et al. (2021) on the Malaysian and Singapore indexes and also similar to the findings of Onyele and Nwadike (2021) on the S\&P Global 1200 index.

It is noticeable that the results of the Premier index values in the EGARCH and TGARCH models are consistent, confirming that there were negative effects on this index's returns as result of negative news during the COVID-19 period.

Table 6. TGARCH $(1,1)$ Model
Variance Equation 
A limitation in this study is that the impact of COVID-19 on Boursa Kuwait market sectors was not tested. Knowing which sectors are most affected by this pandemic will be valuable knowledge and studying this is an opportunity for future research. Future studies may also apply other GARCH models such as the GARCH-X model to extend the understanding of the behavior of volatility on the returns of Boursa Kuwait.

Another important opportunity that was indicated by this research is to apply the asymmetric GARCH models on the Gulf Equity markets during the COVID-19 period to have a comparative result of the volatility of these markets.

\section{REFERENCES}

[1] Al Mesfer Al Ajmi, M. M. (2021). Estimating return volatility of stock market indices: the case of Boursa Kuwait. International Journal of Business and Management Research, 9(1), 74-84. DOI: 10.37391/IJBMR.090111.

[2] Alzyadat J. A., Abuhommous, A., \& Alqaralleh, H. (2021). Testing the conditional volatility of the Saudi Arabia Stock Market symmetric and asymmetric autoregressive conditional heteroskedasticity (GARCH) approach. Academy of Accounting and Financial Studies Journal, 25(2), 1-9. https://www.researchgate.net/publication/350240859

[3] Bekaert, G., \& Wu, G. (2000). Asymmetric volatility and risk in equity markets. Review of Financial Studies, 13(1), 1-42. http://dx.doi.org/10.1093/rfs/13.1.1

[4] Black, F., \& Scholes, M. (1975). Asset speculative prices. Journal of Business, 7, 307-324.

[5] Bora, D., \& Basistha, D. (2021). The outbreak of COVID-19 pandemic and its impact on stock market volatility: evidence from a worst-affected economy. Journal of Public Affairs, 1-10. https://doi.org/10.1002/pa.2623

[6] Bollerslev, T. (1986). Generalized autoregressive conditional heteroskedasticity. Journal of Econometrics, 31 (3), 307-327. Available at: https://doi.org/10.1016/0304-4076(86)90063-1.

[7] Boursa Kuwait. (March 2020). All Share Price Index values and the Boursa Kuwait Annual Report 2020. Retrieved from www.boursakuwait.com.kw

[8] Brooks, C., \& Rew, A. G. (2002). Testing for a unit root in a process exhibiting a structural break in the presence of GARCH errors. Computational Economics 20, 157-76. https://doi.org/10.1023/A:1020945428824

[9] Chaudhary, R., Bakhshi, P., \& Gupta, H. (2020). Volatility in International Stock Markets: An Empirical Study during COVID-19. Journal of Risk and Financial Management 13(9), 208. https://doi:10.3390/jrfm13090208

[10] Choo, W. C., Lee, S.-N., \& Ung, S. N. (2011). Macroeconomics uncertainty and performance of GARCH models in forecasting Japan stock market volatility. International Journal of Business and Social Science. 2 (1), 200-208.

[11] Czech, K., Wielechowski, M., Kotyza, P., Benešová, I., \& Laputková, A. (2020). Shaking stability: COVID-19 impact on the Visegrád Group countries' financial markets. Sustainability, 12(15). https://doi:10.3390/su12156282

[12] Deutsche Börse Group. (March 15 2020). Frankfurt stock exchange Dax index values. Retrieved from https:Ildeutscheboerse.com
[13] Dickey, D. A., \& Fuller, W. A. (1981). Likelihood ratio statistics for autoregressive time series with a unit root. Econometrica, 49(4), 1057-1072. https://doi.org/10.2307/1912517

[14] Ding, Z., Granger, C W. J. and Engle, R. F. (1993). A Long Memory Property of Stock Market Returns and a New Model. Journal of Empirical Finance, 1:83-106.

[15] Engle, R. F. (1982). Autoregressive conditional heteroscedasticity with estimates of the variance of United Kingdom inflation. Econometrica, 50(4), 987-1008. https://doi.org/10.2307/1912773

[16] Ganguly, S. (2020). Estimation of volatility and leverage effect during the outbreak of Covid-19 pandemic: A study based on selected international stock markets. Indo-Asian Journal of Finance and Accounting, 1(2), 177-187.

[17] Glosten, L. R., Jagannathan, R., \& Runkle, D. E. (1993). On the relation between the expected value and the volatility of the nominal excess return on stocks. The Journal of Finance, 48(5), 1779-1802. https://doi.org/10.1111/j.1540-6261.1993.tb05128.x

[18] Goodell, J. W. (2020). COVID-19 and finance: Agendas for future research. Financial Research Letters, 35, 101512. https://doi.org/10.1016/j.frl.2020.101512

[19] Hoshi, T., \& Kashyap, A. K. (2004). Japan's financial crisis and economic stagnation. Journal of Economic Perspectives, 18(1), 3-26. https://doi.org/10.1257/089533004773563412

[20] Kuwait News Agency. (December 2020). News on economic recovery in Kuwait. Retrieved from www.kuna.net.kw

[21] London Stock Exchange. (March 14 2020). FTSE Index of the London Stock Exchange values. Retrieved from https: Ilondonstockexchange.com

[22] McMillan, D. G., \& Speight, A. E. H. (2003). Asymmetric volatility dynamics in high frequency FTSE-100 stock index future. Applied Financial Economics, 13(8), 599-607. https://doi.org/10.1080/0960310022000040715

[23] Nelson, D. B. (1991). Conditional heteroskedasticity in asset returns: a new approach. Econometrica, 59(2), 347-370. https://doi.org/10.2307/2938260

[24] New York Stock Exchange. (March 11 2020). Dow Jones Industrial average index values. Retrieved from https: Iwww.nyse.com

[25] Nicholls, D., \& Tonuri, D. (1995). Modeling stock market volatility in Australia. Journal of Business Finance and Accounting, 22(3), 377-396. https://doi.org/10.1111/j.14685957.1995.tb00880.x

[26] Nurdany, A., Ibrahim, M. H., \& Romadoni, M. F. (2021). The asymmetric volatility of the Islamic capital market during Covid-19 Pandemic. Journal of Islamic Monetary Economics and Finance, 7(SI 1 1)187. https://doi.org/10.21098/jimf.v7i0.1312

[27] Ogege, S. M. (2016). Gauging the volatility level of stock returns in the Nigerian stock market. The Pacific Journal of Science and Technology, 17(1), 118-120. http://www.akamaiuniversity.us/PJST17_1_120.pdf

[28] Olbrys, J., \& Majewska, E. (2017). Asymmetry effects in volatility on the major European Stock Markets: the EGARCH based approach. Quantitative Finance and Economics, 1(4), 411-427. https://doi.org/10.3934/QFE.2017.4.411

[29] Onyele, K. O., \& Nwadike, E. C. (2021). Modelling stock returns volatility and asymmetric news effect: a global 
perspective. Financial Risk and Management Reviews, 7(1), 115. https://doi.org/10.18488/journal.89.2021.71.1.15

[30] Poon, S. H., \& Granger, C. W. J. (2003). Forecasting volatility in financial markets: a review. Journal of Economic Literature, (478-539). https://doi.org/10.1257/002205103765762743

[31] Sanyal, P. K., \& Gahan, P. (2016). Volatility behaviour in emerging stock markets - A GARCH Approach. International Journal of Business Analytics and Intelligence, 4(2), 21-35, https://www.academia.edu/38147523

[32] Sentana, E. (1995). Quadratic ARCH models. Review of Economic Studies, 62(4), 639-661. https://doi.org/10.2307/2298081

[33] Tsay, R. S. (2010). Principal component analysis and factor models. Analysis of Financial Time Series, 3rd ed. Hoboken, New Jersey, US: John Wiley \& Sons, 467-504.

[34] Yong, J. N. C., Ziaei, S. M., \& Szulczyk, K. R. (2021). The impact of COVID-19 pandemic on stock market return volatility: evidence from Malaysia and Singapore. Asian Economic and Financial Review, 11(3), 191-204. https://doi.org/10.18488/journal.aefr.2021.113.191.204

[35] Yousef, I., \& Shehadeh, E. (2020). The impact of COVID-19 on gold price volatility. International Journal of Economics and Business Administration, 8(4), 353-364.
[36] Zakoian, J. M. (1994). Threshold heteroskedastic models. Journal of Economic Dynamics and Control, 18(5), 931-955. https://doi.org/10.1016/0165-1889(94)90039-6

[37] Dr. Dean Michael Aguon and Dr. Nam Phuong Le (2021), A Phenomenological Study on Nurses' Perception of Compensation Received During Covid-19 Pandemic. IJBMR 9(4), 443-447. DOI: 10.37391/IJBMR.090407.

[38] Costas Siriopoulos (2021), Financial Markets are not efficient: Financial Literacy as an Effective Risk Management Tool. IJBMR 9(1), 65-73. DOI: 10.37391/IJBMR.090110.

[39] Thouraya Snoussi (2020), Social Media for Crisis Communication Management. IJBMR 8(3), 64-72. DOI: 10.37391/IJBMR.080302.

[40] World Health Organization. (March 2020). COVID-19 statistics. Retrieved from https://www.who.int

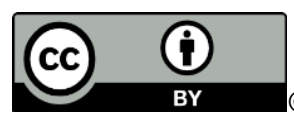

2021 by the Mesfer Mahdi Al Mesfer Al Ajmi. Submitted for possible open access publication under the terms and conditions of the Creative Commons Attribution (CC BY) license (http://creativecommons.org/licenses/by/4.0/). 